\title{
28 Research Soure \\ Hypoglossal schwannoma masquerading as a submandibular gland tumor: a case report
}

\section{Yanming Weng}

General Hospital of Central Theater of PLA https://orcid.org/0000-0003-0659-1991

\section{Sainan Li}

Second Xiangya Hospital

\section{Hanjiang Wu}

Second Xiangya Hospital

Kun Wu ( $\nabla$ wukun1302@sina.com )

Second Xiangya Hospital https://orcid.org/0000-0002-9468-5121

\section{Case report}

Keywords: Case report, Hypoglossal nerve, Schwannoma, Submandibular space

Posted Date: March 29th, 2021

DOI: https://doi.org/10.21203/rs.3.rs-250718/v2

License: (9) This work is licensed under a Creative Commons Attribution 4.0 International License. Read Full License 


\section{Abstract}

Background: Hypoglossal nerve schwannoma in the submandibular space is rare. This case report presents the treatment of a young patient affected by an unusual hypoglossal nerve schwannoma at the right side of the submandibular region.

Case representation: A 31-year-old female presented to our department with complaints of a right-sided submandibular region mass. None calculi was observed by CBCT. An MRI of the neck demonstrating a $18 \times 12 \mathrm{~mm}$ mass located at the submandibular region. Based on clinical presentation and imaging, a diagnosis of a submandibular gland tumor was conferred and the patient scheduled for excision. Intraoperatively, the mass was noted to arise from the hypoglossal nerve, remaining independent of the submandibular gland. On histopathologic analysis, the mass was determined to be consistent with hypoglossal schwannoma.

Conclusion: Though rare, the hypoglossal schwannoma should remain a consideration in the evaluation of a submandibular space mass. During operation, it might be better to explore the mass before managing the submandibular gland.

\section{Background}

Schwannomas are histologically benign, slowly growing tumors of the myelin-producing Schwann cells in the peripheral nervous system ${ }^{1}$. The schwannomas most commonly reported in the vestibular nerve ${ }^{2}$, while the motor nerve schwannomas are rare. Hypoglossal nerve schwannomas account for less than $5 \%$ of all head and neck schwannomas ${ }^{3}$.The tumor could arise from any portion of the nerve throughout its course $^{4}$. Kaye et al. classified schwannomas into three subtypes based on the location: type A intracranial, type B - intracranial/extracranial, and type $\mathrm{C}$-extracranial ${ }^{4}$. Type $\mathrm{B}$ is the commonest type and often described as dumb-bell shaped schwannoma. The common presenting symptom of patients with hypoglossal schwannomas is a neck mass, as well as hypoglossal nerve paralysis on clinical examination ${ }^{5}$. Hypoglossal nerve schwannoma in the submandibular space is rare. Here, we presented a hypoglossal nerve schwannoma in a young female in the right side of the submandibular region.

\section{Case Report}

The study was approved by the institutional review board of the Second Xiangya Hospital and informed consent was obtained from the patient. A 31-year-old female was referred to the second Xiangya Hospital with a progressively enlarging right-sided neck mass. The feeling of slight pain in the right submandibular region had lasted for 6 months. She had no history of dysphagia or hypoglossal nerve paralysis related symptoms. The clinical examination showed a mobile and soft mass with an approximate size of $1.5 \mathrm{~cm}$ $\times 2 \mathrm{~cm}$. The right Wharton's duct and Neurological examination were normal. No submandibular salivary gland calculus was found by cone - beam computed tomographic (CBCT). Magnetic resonance imaging (MRI) scan revealed that a $1.8 \mathrm{~cm} \times 1.2 \mathrm{~cm}$ sized mass with a clear border located at the right 
submandibular space. The mass was partly coated by the submandibular gland (Fig. 1a). Moreover, the lesion was isointense on T1 and hyperintense on fat-suppressed T2 images (Fig. 1b-c). After injecting contrast medium, the bulk homogeneously enhanced (Fig. 1d).

According to the radiographic characteristics and clinical palpation of the lesion, a preliminary diagnosis of the lesion was a submandibular gland benign tumor. The surgical treatment plan was treated with submandibular gland and tumor excision. Surgical treatment was performed using a standard submandibular approach. When the submandibular gland was separated from the deep tissue, we found the mass arose from the hypoglossal nerve and well capsulated (Fig. 2a-b). Then, the operator excised the tumor in hypoglossal nerve subcapsular dissection with preservation of the hypoglossal nerve and submandibular salivary gland (Fig. 3a-b).

The histopathological examination after operation showed a mixture of Antoni type A and Antoni type B (Fig. 4) in accordance with the diagnosis of a hypoglossal schwannoma. Antoni type $A$ is composed of spindle shaped Schwann cells with elongated nuclei arranged in streams and nuclear palisades known Verocay bodies. Antoni type B consists of less spindle cells and a myxoid background ${ }^{6}$.

The patient had the complication that the apex of tongue was slightly deviated to the right side after the operation (Fig. 5a). The complication was relieved with the follow-up period of three months (Fig. 5b).

\section{Discussion}

Schwannomas are benign neoplasms of the myelin-producing Schwann's cells which are always slow growing and affect sensory nerves ${ }^{7}$. Extracranial hypoglossal nerve schwannomas are exceedingly rare and have a greater preponderance among women ${ }^{8-10}$. The case in this study have similar characteristics with the previous studies.

Extracranial hypoglossal nerve schwannomas often present as a solitary, painless neck mass in the neck $^{11}$. Most of the patients commonly have tongue deviation and speech disturbance, but small portion of the patients presented without any neurological symptoms ${ }^{10}$. In this study, the patient didn't have the history of the tongue deviation.

According to history the pain of patient, we speculated that the patient was submandibular lymphandenitis in priority. However, negative findings on CBCT reduced the possibility of submandibular lymphandenitis.

MRI played an key role in preoperative diagnosis of the tumor and was the most frequently used imaging modality ${ }^{10}$. Hypoglossal nerve schwannomas exhibit hypointense or isointense on $\mathrm{T} 1$, hyperintense on $\mathrm{T} 2$, with heterogeneous enhancement on contrast-enhanced studies ${ }^{4,12,13}$. That was consistent with the findings presented in our study. The location of the lesion was deep and tightly close to the igastric intermediate tendon. Pleomorphic adenomas, which frequently present in the submandibular gland, have similar MRI image with Hypoglossal nerve schwannomas ${ }^{14}$. This suggested that the MRI findings of 
hypoglossal nerve schwannomas were not specific ${ }^{15}$. The patient was diagnosed preoperatively as a submandibular gland tumor base on the symptom and MRI findings.

Surgical treatment is universally accepted for submandibular gland tumor and the hypoglossal schwannoma. During the operation, we found that the mass separated from submandibular gland and located in hypoglossal nerve. Then, the tumor was excised with preservation of hypoglossal nerve and submandibular gland. Due to the limit reports, the outcomes in nerve preservation versus sacrifice during surgical resection were uncertain $\varangle$ but the overall outcomes in both are favorable ${ }^{10}$. If the hypoglossal schwannoma was identified preoperatively, the smaller surgical incision could be performed for only dissecting hypoglossal nerve and tumor. The diagnosis was confirmed as a hypoglossal schwannoma histopathologically by the presence of Antoni A fibers, which are narrow elongated bipolar cells, and Antoni $B$ fibers, which are less organized and distributed cells ${ }^{2,6}$. Microscopically, in this case, it contained a mixture of Antoni A fibers and Antoni B cells.

\section{Conclusion}

Hypoglossal schwannomas are rare tumors and limit reports have been described in the literature. If images showed that the tumor coated by submandibular gland, it would be better to explore the lesion initially rather than resect the submandibular gland. The goal of surgery should be total resection of the tumor with preservation of nerve function. Progress after surgery tends to be favorable.

\section{Abbreviations}

CBCT: cone - beam computed tomographic; MRI: Magnetic resonance imaging

\section{Declarations}

\section{Ethics approval and consent to participate}

Not applicable

\section{Consent for publication}

Not applicable

\section{Availability of data and materials}

Not applicable

\section{Competing interests}

The authors declare that they have no competing interests

\section{Funding}


This research received no sources of funding.

\section{Authors' contributions}

Conceptualization: Yanming Weng, Hanjiang Wu, Kun Wu; Writing-Original Draft Preparation:

Yanming Weng, Sainan Li; Writing-Review \& Editing: Hanjiang Wu, Kun Wu. All authors have approved the final version of the manuscript.

\section{Acknowledgements}

This research did not receive any specific grant from funding agencies in the public, commercial, or not-for-profit sectors.

\section{Author information}

1 Department of stomatology, General Hospital of Central Theater of PLA. Wuhan, Hubei 410070, PR China. | 491594500@qq.com

2 Department of Oral and Maxillofacial Surgery, the Second Xiangya Hospital, Central South University, Changsha, Hunan 410011, PR China.

\section{References}

1. De Foer B, Hermans R, Sciot R, Fossion E, Baert AL. Hypoglossal schwannoma. Ann Otol Rhinol Laryngol. 1995. 104(6): 490-2.

2. Rachinger J, Fellner FA, Trenkler J. Dumbbell-shaped hypoglossal schwannoma. A case report. Magn Reson Imaging. 2003. 21(2): 155-8.

3. Lee MK, Sidell DR, Mendelsohn AH, Blackwell KE. Hypoglossal schwannoma masquerading as a carotid body tumor. Case Rep Otolaryngol. 2012. 2012: 842761.

4. Suri A, Bansal S, Sharma BS, et al. Management of hypoglossal schwannomas: single institutional experience of 14 cases. J Neurol Surg B Skull Base. 2014. 75(3): 159-64.

5. Manfredi M, Merigo E, Pavesi G, Macaluso GM, Vescovi P. Tongue lesions and isolated hypoglossal nerve palsy: a case report. Oral Surg Oral Med Oral Pathol Oral Radiol Endod. 2007. 104(2): e18-20.

6. Fornaro R, Salerno A, Filip DC, Caratto E, Caratto M, Casaccia M. Schwannoma of the hypoglossal nerve: Review of the literature based on an illustrative case. Mol Clin Oncol. 2017. 7(2): 288-294.

7. Plitt A, El Ahmadieh TY, Bindal S, Myers L, White J, Gluf W. Hypoglossal Schwannoma of Neck: Case Report and Review of Literature. World Neurosurg. 2018. 110: 240-243.

8. Smith PG, Backer RJ, Kletzker GR, et al. Surgical management of transcranial hypoglossal schwannomas. Am J Otol. 1995. 16(4): 451-6. 
9. Hoshi M, Yoshida K, Ogawa K, Kawase T. Hypoglossal neurinoma-two case reports. Neurol Med Chir (Tokyo). 2000. 40(9): 489-93.

10. Bindal S, El Ahmadieh TY, Plitt A, et al. Hypoglossal schwannomas: A systematic review of the literature. J Clin Neurosci. 2019. 62: 162-173.

11. Ram H, Agrawal SP, Husain N, Chakrabarti S. Hypoglossal schwannoma of parapharyngeal space: an unusual case report. J Maxillofac Oral Surg. 2015. 14(Suppl 1): 73-6.

12. Flickinger FW, Lozano RL, Yuh WT, Sachs MA. Neurilemoma of the tongue: MR findings. J Comput Assist Tomogr. 1989. 13(5): 886-8.

13. Nonaka Y, Grossi PM, Bulsara KR, Taniguchi RM, Friedman AH, Fukushima T. Microsurgical management of hypoglossal schwannomas over 3 decades: a modified grading scale to guide surgical approach. Neurosurgery. 2011. 69(2 Suppl Operative): ons121-40; discussion ons140.

14. Wakabayashi N, Umezawa H, Matsumoto NM, Endo Y, Naito Z, Ogawa R. Low-grade Cribriform Cystadenocarcinoma: A Review of the Literature and Case Report. Plast Reconstr Surg Glob Open. 2017. 5(4): e1306.

15. Bamgbose BO, Sato A, Yanagi Y, et al. A Case of Schwannoma of the Submandibular Region. Open Dent J. 2018. 12: 12-18.

\section{Figures}



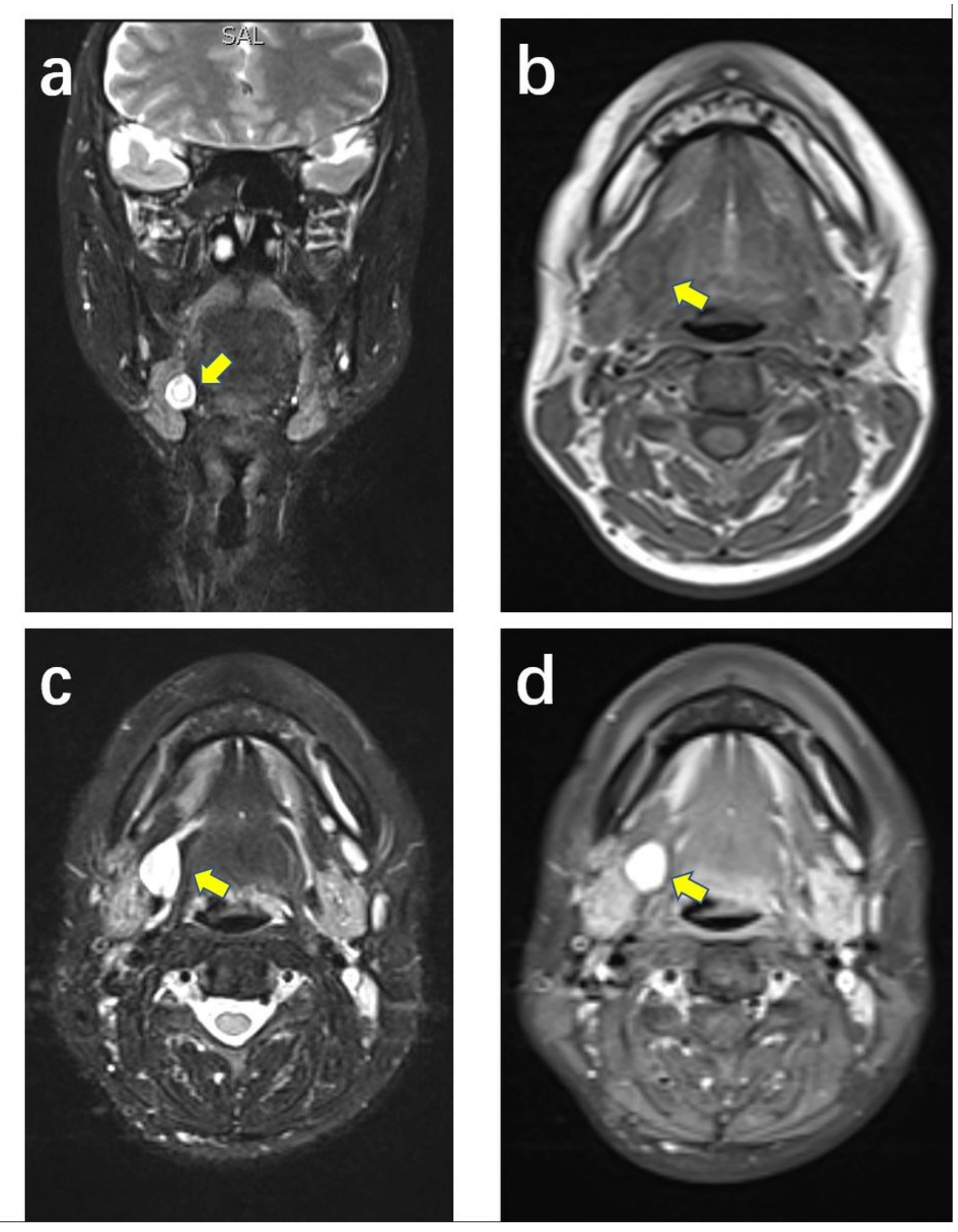

\section{Figure 1}

MRI findings. (a) Coronal T2 WI showing a hyperintense lesion in the submandibular space 『yellow arrow). The lesion was partly coated by the submandibular gland. (b) Axial T1 WI showing a isointense lesion close to the inside of the submandibular gland囚yellow arrow). (c) Axial fat-suppressed T2 WI showing hypertense lesion छyellow arrow). (d) Axial contrast fat-suppressed T2 WI showing an enhancing lesion at the area छyellow arrow). 

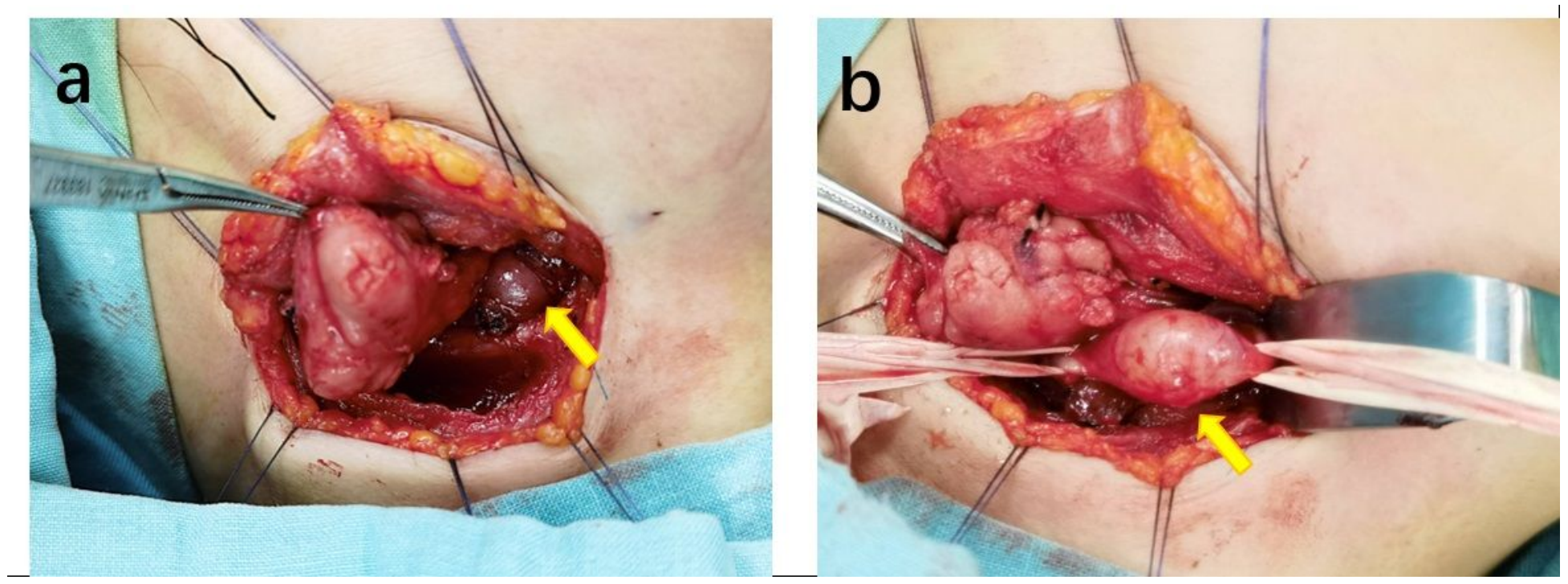

Figure 2

(a) Tumor mass exposed囚yellow arrow). (b) the mass arosed from the hypoglossal nerve and well capsulated 区yellow arrow).

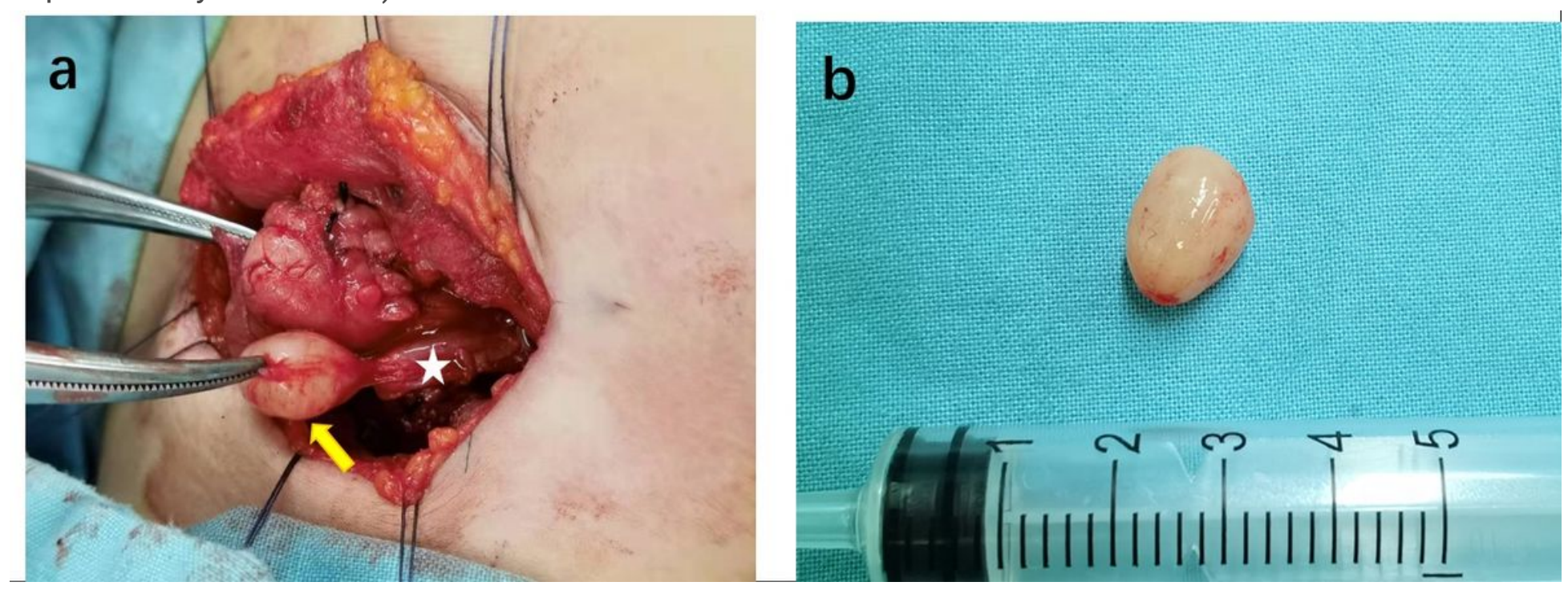

\section{Figure 3}

(a) The tumor 区yellow arrow) was completely dissected from the hypoglossal nerve邓white star). (b) Excised tumor specimen. 


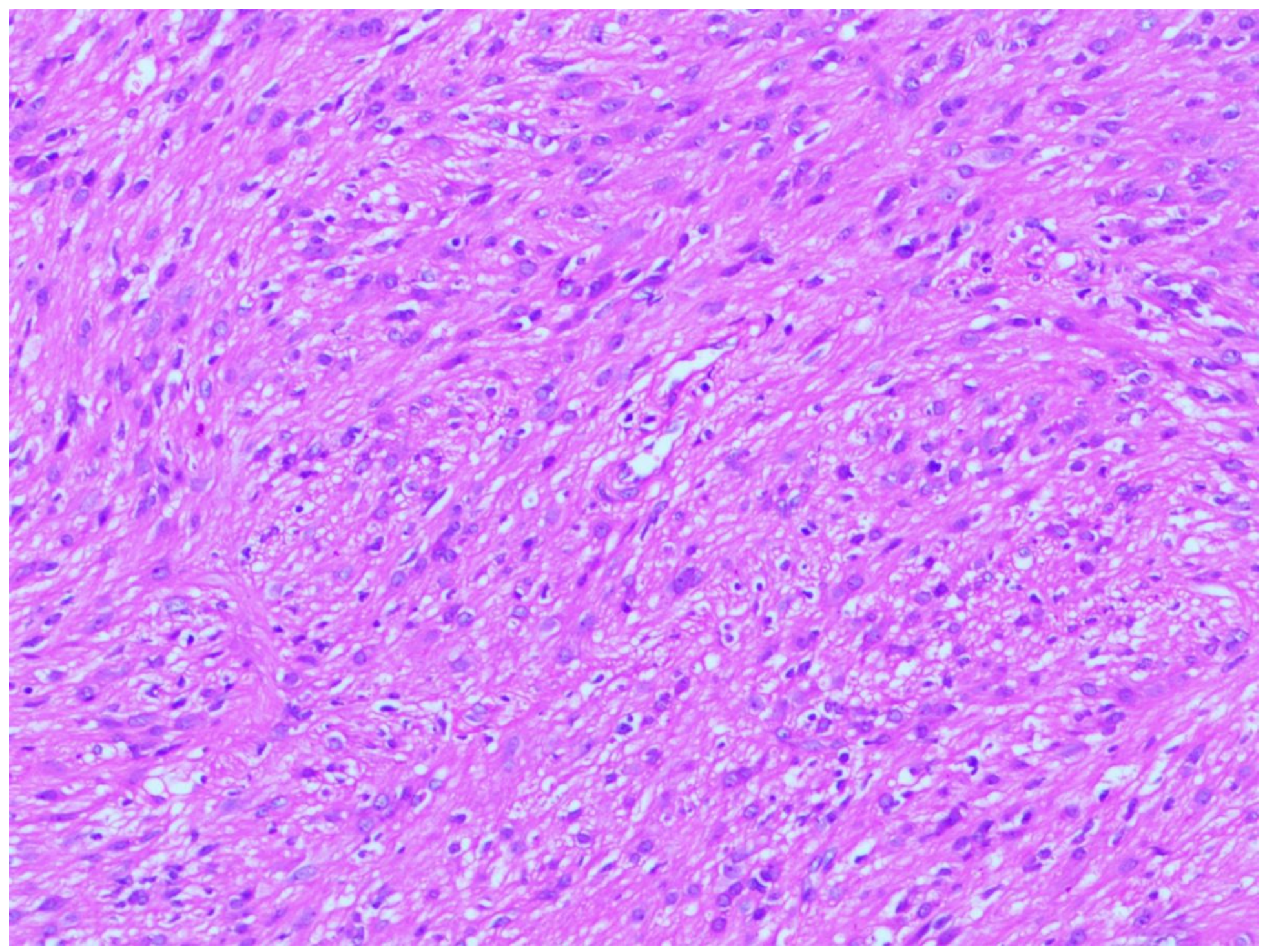

\section{Figure 4}

H\&E staining of tumor showing Antoni $A$ and $B$ type of tissues 


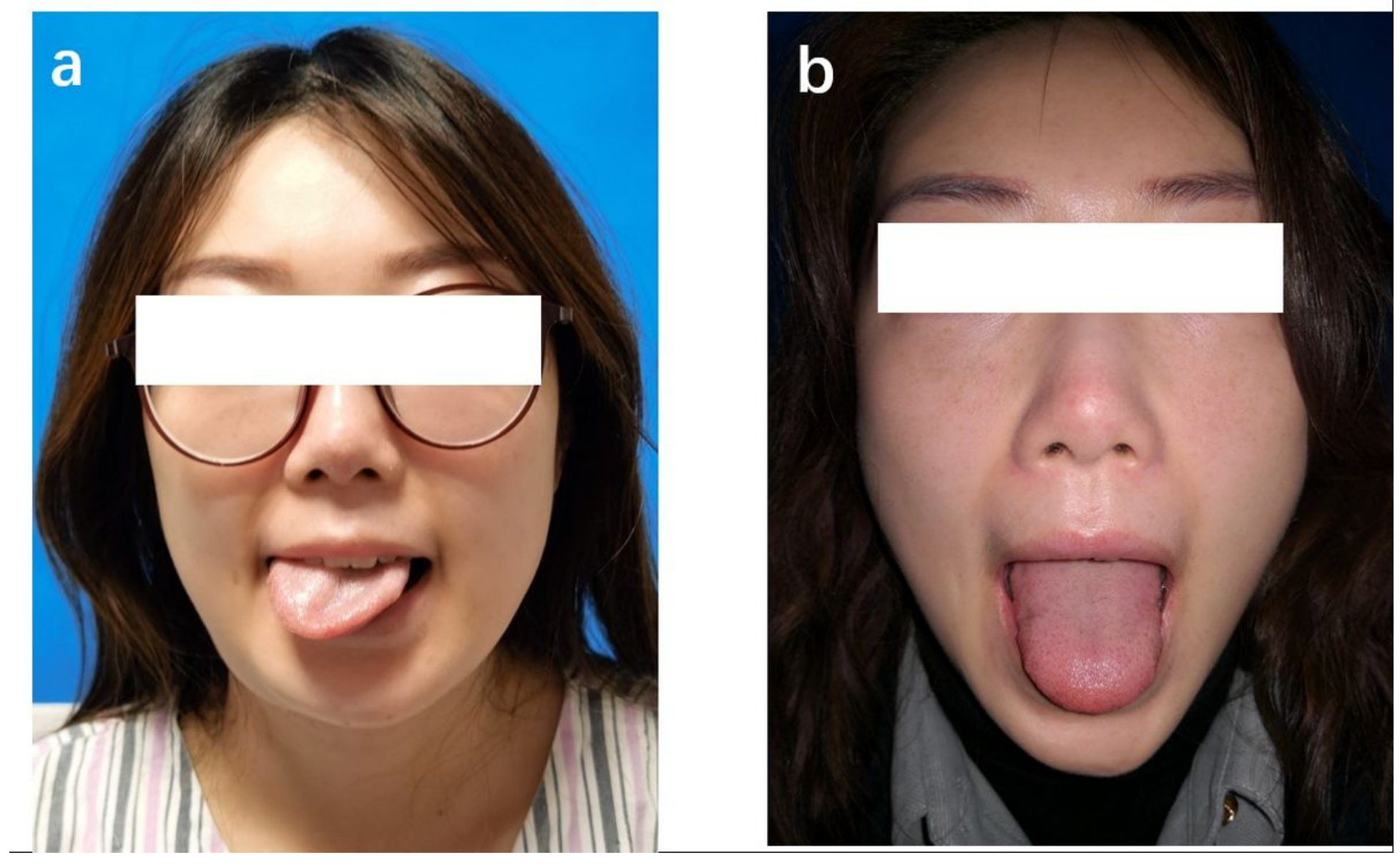

Figure 5

(a) the apex of tongue was slightly deviated to the right side after the operation. (b) no tongue deviation after three-month follow-up 